\title{
Denonvilliers' fascia acts as the fulcrum and hammock for continence after radical prostatectomy
}

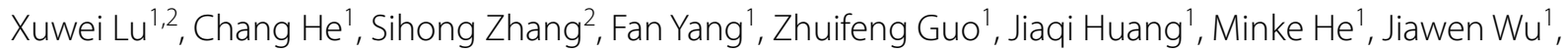
Xia Sheng ${ }^{3}$, Wenyao Lin ${ }^{4}$, Jie Cheng ${ }^{4}$, Jianming Guo ${ }^{2^{*}}$ and Hang Wang ${ }^{2^{*}}$

\begin{abstract}
Background: Radical prostatectomy (RP) is the primary treatment of localized prostate cancer. Immediate urinary incontinence post-RP was still common and depressing without specific reason.

Methods: A multicenter cohort of 154 consecutive patients from 2018 to 2020, who was diagnosed with localized prostate cancer underwent either modified mini-incision retropubic radical prostatectomy (Mmi-RRP) or laparoscopic radical prostatectomy (LRP) or robotic-assisted radical prostatectomy (RARP). Seventy-two patients with Denonvilliers' fascia (DF) spared were included in DFS (Denonvilliers' fascia sparing) group. Whereas eighty-two patients with DF completely or partially dissected were set as Group Control. The primary outcome was immediate continence (ImC). Continuous data and categorical data were analyzed with t-test and Chi-square test, respectively. Odds ratios (ORs) were calculated with logistic regression.
\end{abstract}

Results: Urinary continence of Group DFS was significantly better than that of Group Control at each time point within one year after operation. Incidence rate of continence in Group DFS and Group Control were 83.3\% vs 13.4\% $(P<0.01)$ for ImC, $90.3 \%$ vs $30.5 \%(P<0.01)$ at 3 months, $91.7 \%$ vs $64.6 \%(P<0.01)$ at 6 months, and $93.1 \%$ vs $80.5 \%$ $(P=0.02)$ at 1 year after operation, respectively. Positive surgical margin (PSM) showed no significant difference (20.8\% vs $20.7 \%, P=1.0)$. In multivariate analysis, DFS showed importance for $\operatorname{ImC}$ post $\operatorname{RP}(O R=26.4, P<0.01)$.

Conclusions: Denonvilliers' fascia acted as the fulcrum and hammock for continence post RP. Preservation of DF contributed to better continence after RP without increase of PSM.

Trail registration Our research was conducted retrospectively and approved by the ethical committees of Minhang Hospital, but not registered.

Keywords: Prostate cancer, Prostatectomy, Denonvilliers' fascia, Urinary continence, Positive surgical margin

*Correspondence: guo.jianming@zs-hospital.sh.cn; wang.hang@zs-hospital. sh.cn

2 Department of Urology, Zhongshan Hospital, Fudan University, Fenglin Rd 130, Shanghai 200032, China

Full list of author information is available at the end of the article

\begin{abstract}
Introduction
Prostate cancer $(\mathrm{PCa})$ is the top-ranking malignant tumor for men worldwide [1]. Radical prostatectomy (RP) is the primary therapeutic choice for localized PCa. Dramatic improvement of surgery technique and more application of newer devices have reduced the incidence of severe complications for RP. Unfortunately, incontinence after $\mathrm{RP}$, which haunted patients extremely hard, is still a huge challenge. The morbidity of incontinence one-year after
\end{abstract}

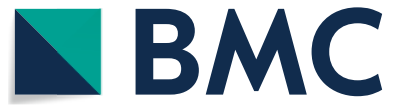

(c) The Author(s) 2021. Open Access This article is licensed under a Creative Commons Attribution 4.0 International License, which permits use, sharing, adaptation, distribution and reproduction in any medium or format, as long as you give appropriate credit to the original author(s) and the source, provide a link to the Creative Commons licence, and indicate if changes were made. The images or other third party material in this article are included in the article's Creative Commons licence, unless indicated otherwise in a credit line to the material. If material is not included in the article's Creative Commons licence and your intended use is not permitted by statutory regulation or exceeds the permitted use, you will need to obtain permission directly from the copyright holder. To view a copy of this licence, visit http://creativecommons.org/licenses/by/4.0/. The Creative Commons Public Domain Dedication waiver (http://creativecommons.org/publicdomain/zero/1.0/) applies to the data made available in this article, unless otherwise stated in a credit line to the data. 
RP remains up to $21 \%$, regardless whether open radical prostatectomy (ORP) or laparoscopic radical prostatectomy (LRP) or robotic-assisted radical prostatectomy (RARP) has been taken [2]. Although many researchers have proposed many factors that might matter such as sphincter, length of membrane urethra, bladder neck preservation, neurovascular bundle (NVB) sparing, and Denonvilliers' fascia (DF) as well, that is still uncertainty about the mechanism of post RP continence [3].

Furthermore, most literatures reported continent rate of short-term, mid-term and long-term post RP. As to immediate continence ( $\operatorname{ImC}$ ), few reports could be found. We have applied a new technique as DF-sparing (DFS) since 2018 in RP with excellent urinary continence, especially the ImC. Because of the encouraging outcome of urinary control, there must be something worth thinking about. So, we analyzed the data to explore the mechanism of continence post RP and the role of DF in it, as well as the feasibility and safety of DFS.

\section{Methods}

From January 2018 to October 2020, 154 consecutive patients with localized prostate cancer underwent RP in Zhongshan Hospital, Minhang Hospital and Xuhui Hospital, FUDAN University. All the patients were given bone scan or PET-CT and excluded with metastasis before operation. The majority of patients completed MRI before operation except for those with contraindications including metal implantation and claustrophobia. Any suspicious sign showing that prostate capsule was invaded whether in radiology or in surgery, especially at the lateral-posterior direction, DF sparing was not recommended. If tumor was localized and prostate capsule wasn't invaded, DFS technique was available. Seventytwo cases that underwent either modified mini-incision retropubic radical prostatectomy (Mmi-RRP) or LRP or RARP with DFS were included in Group DFS. Group Control included 82 cases received Mmi-RRP/LRP/ RARP with DF completely or partially dissected.

All the procedures were completed by three experienced surgeons. Due to puncture approach, local invasion or neoadjuvant therapies, DFS was applied to appropriate patients. Urinary catheter was removed 5-7 days after operation. All the patients were followed up for 2-26 (14.5 \pm 6.9$)$ months.

The primary outcome was ImC. All the continence status were assessed by outpatient follow-up. Continent status reported by patients was collected at 1-week, 3-month, 6-month, and 1-year after urethral catheter was discarded. We defined continence as usage of $\leq 1$ pad per $24 \mathrm{~h}$. Considering that urine leakage caused by multiple factors was prevalent shortly after catheter removal, most of which was transient and could recover soon without treatment, we defined $\operatorname{ImC}$ as regaining continence within 1-week after urinary catheter removal [4].

\section{Surgery and post-surgery protocol}

All the procedures were operated out of peritoneal under general anesthesia. The surgical approaches were decided by financial conditions and personal preferences of patients with full knowledge of benefits and risks. MmiRRP was operated with an approximate $7 \mathrm{~cm}$ longitudinal suprapubic incision, whereas LRP or RARP was with 3-4 poles. DF was thought to be composed of multiple layers and ensheathed both seminal vesicles and vas deferens into the anterior layer. After isolation of seminal vesicles, anterior layer of DF was isolated at the level of seminal vesicle triangle, and the dissection was located between prostate capsule (PC) and DF towards prostate apex in order to keep DF intact (Figure 1, Figure $2 \mathrm{f}-\mathrm{h}$ ). For the sake of cavernous nerves protection, blunt dissection was preferred. In consideration of potential nerve fiber damage, energy devices were seldom used during dissection near prostate.

Unfortunately, it was difficult to keep DF intact sometimes. In locally advanced PCa cases, the tight junction between DF and prostate added extra difficulty to LRP procedures. In these situations, DF would be resected partially or completely together with prostate (Fig. 2a-d). As to NVB sparing, careful dissection along PC in postlateral direction should be enforced in some suitable cases.

No bladder neck and anterior and/or posterior reconstruction were conducted in our procedures. It was necessary to dissect close to prostate and keep bladder neck intact. But some situations, for example, locally advanced $\mathrm{PCa}$, big prostate volume, and irregularly shaped prostate could make it hard to keep bladder neck intact. Under these circumstances, reconstruction of bladder neck was made to restore anastomosis, always by suturing bladder neck at 6 o'clock position.

\section{Statistical analysis}

The pathology images were processed with K-viewer version 1.5.3.1 (KFBIO, Zhejiang, CHINA). The continuous data and categorical data were analyzed with $t$-test and Chi-square test, respectively. Kaplan-Meier method was used to compute urinary continence curve. Binary logistic regression analysis was applied to screen predictors for ImC. All data analyses were performed using SPSS 22.0 statistical software (IBM SPSS, Chicago, IL, USA). In all analysis, $P<0.05$ was considered statistically significant. 


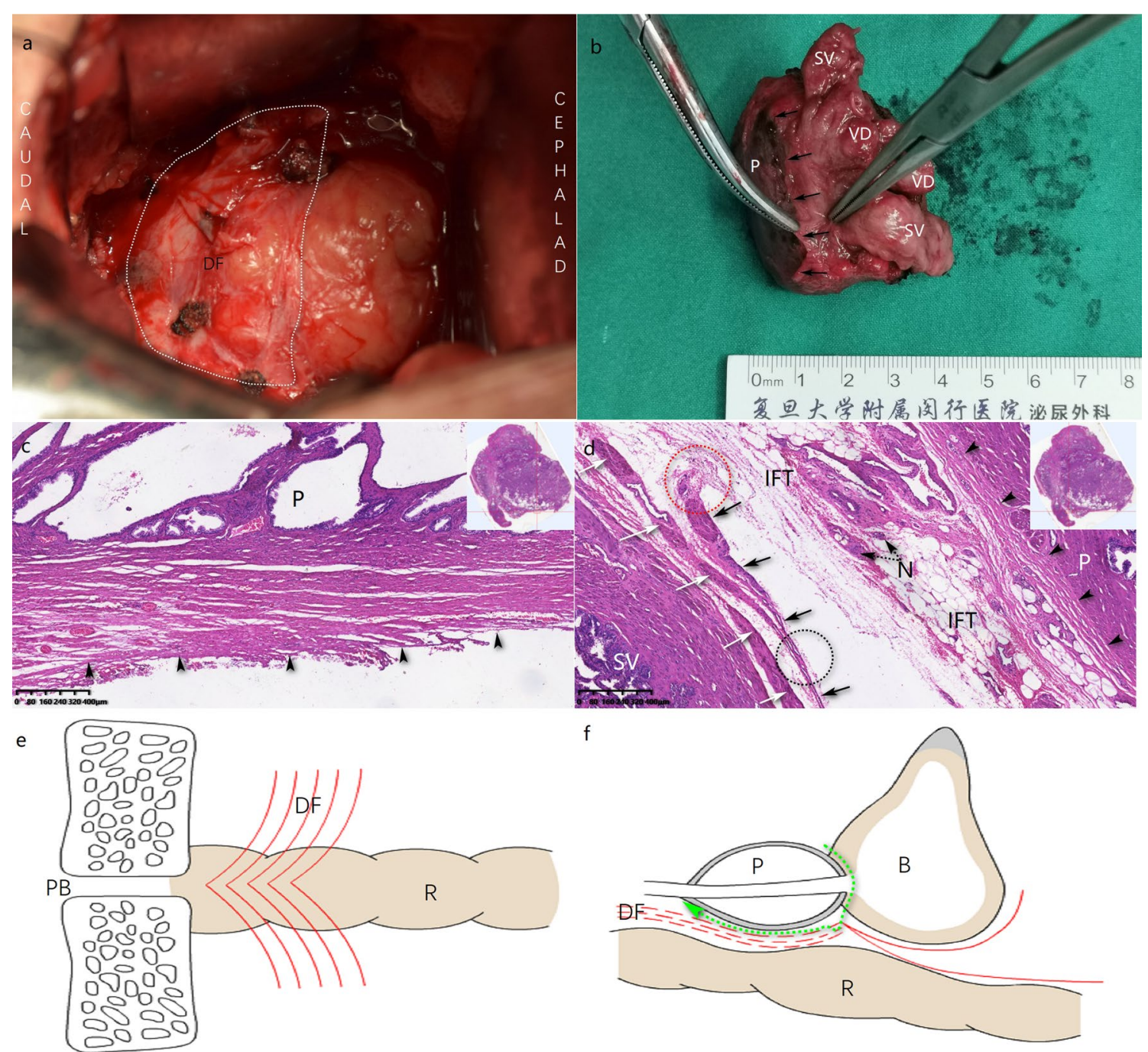

Fig. 1 Scenes of Mmi-RRP procedure with DFS technique and pathological section through paramedian of prostate, stained by HE. a DF (white dot line area) kept intact after prostate removal, also shown on schematic drawing (e). b Anterior layer of DF cut open at seminal vesicles triangle level. Dissection was kept between DF and PC towards apex of prostate. Black arrows exhibited the cut-line of DF's anterior layer. c No DF structure in the backward direction of prostate. $\mathbf{d}$ The cut-line of DF on the pathological section (red dot line circle), fused with seminal vesicle fascia propria (black dot line circle). e, f Schematic drawing OF dissecting bladder and prostate junction (green dot line). B: bladder; HE: hematoxylin and eosin; IFT: inter fascial tissue; N: nerve; P: prostate; PB: pubic bone; PC: prostate capsule; R: rectum; SV: seminal vesicles; VD: vas deferens. Black arrow: DF; Black arrow head: $P C$; White arrow: seminal vesicle fascia propria

\section{Results}

All the 154 consecutive patients completed RRP successfully and were followed-up for $(14.5 \pm 6.9)$ months, ranging from 2 to 26 months. The demographic and tumor characteristics of patients were shown in Table 1, while the details of procedures and pathology in Table 2. There was shorter duration of surgery $(P<0.01)$, more NVB sparing $(P<0.01)$, and less seminal vesicle invasion $(P=0.04)$ in Group DFS vs Group Control. Especially, the post-surgery continence condition was better in Group DFS than in Group Control at each time point from
ImC to 3 months, 6 months $(P<0.01)$ and 12 months $(P=0.02)$, showed in Fig. 3 .

In univariate analysis, surgery type $(O R=1.2-13.0$, $P<0.01)$, surgery duration $(O R=1.0, P<0.01)$, IIEF-5 Q2 pre-surgery $(O R=1.4, P=0.03)$, Gleason score $(O R=0.7$, $P=0.02)$, SV invasion $(O R=0.2, P<0.01)$, NVB sparing $(\mathrm{OR}=2.1-4.8, P=0.01)$ and $\mathrm{DF}$ sparing $(O R=32.3$, $P<0.01)$ were significantly related with $\operatorname{ImC}$. While in multivariate analysis, only DF sparing was proved to be statistically significant for $\operatorname{ImC}, O R=26.4, P<0.01$ (Table 3). 


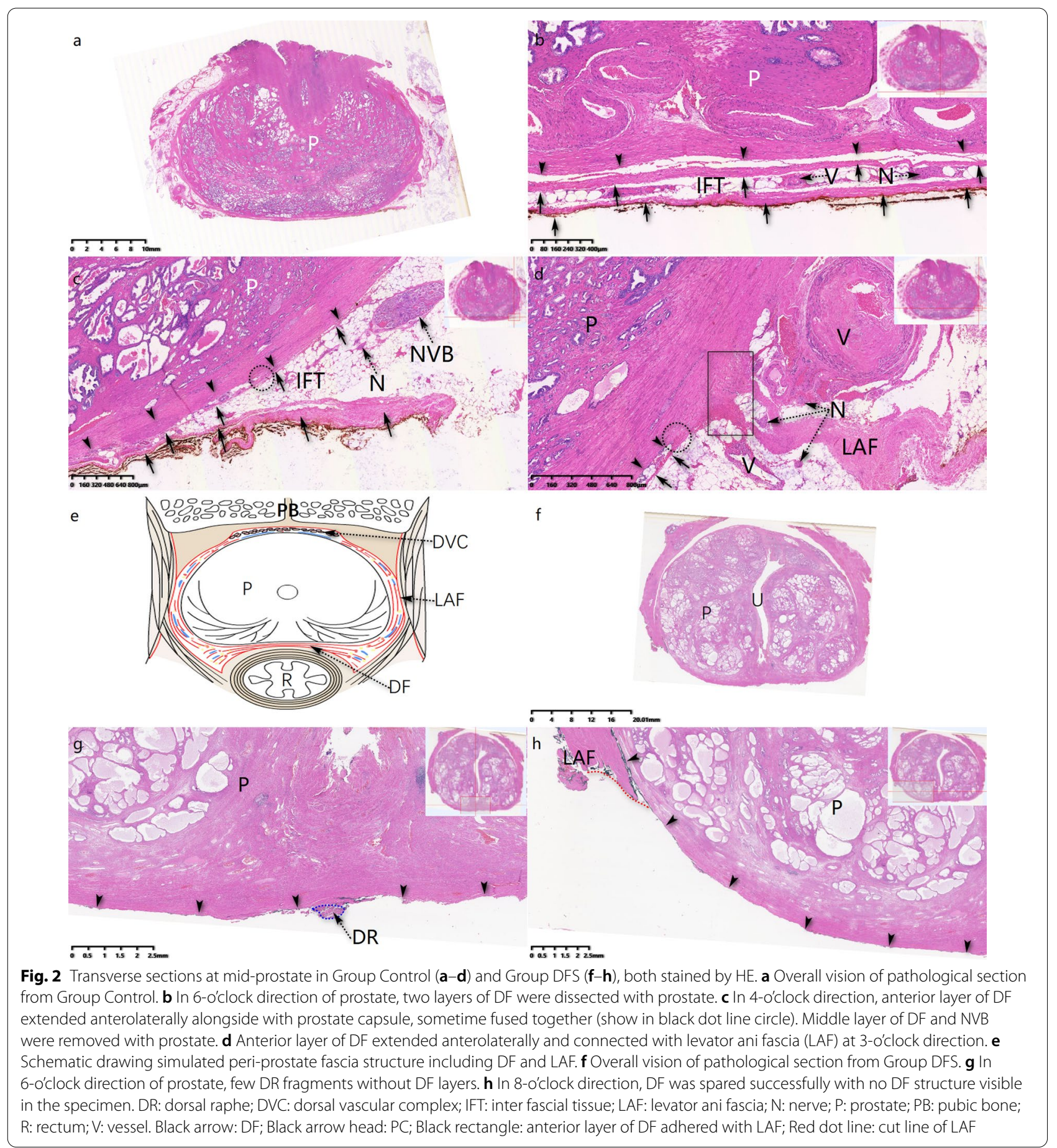

As to definition of sexual dysfunction, we used cutoff value between response 2 and 3 for question NO.2 in IIEF-5 [2]. There were more potent patients in Group DFS than in Group Control at 12 months post-surgery, (34.7\% vs $17.1 \%, P=0.01$ ). No statistical difference of PSM was found between two groups $(20.8 \%$ vs $20.7 \%$, $P=1.0$, Table 2).

\section{Discussion}

Tumor control, urinary continence and sexual potency make up the Trifecta of RP. Post-surgery incontinence is one of the most functionally devastating complications, which could make patients too depressed to maintain social relationship and can even lead to suicide. Albkri A et al. [5] figured out that $28.1 \%$ patients regretted for 
Table 1 Demographics and tumor characteristics of patients

\begin{tabular}{|c|c|c|c|}
\hline & Group DFS $(n=72)$ & Group Control $(n=82)$ & $P$ \\
\hline \multicolumn{4}{|l|}{ Mean \pm Std (Range) } \\
\hline Age, years & $67.8 \pm 5.0(58-79)$ & $69.3 \pm 6.5(54-80)$ & 0.1 \\
\hline BMl & $24.5 \pm 2.6(17.4-30.9)$ & $24.5 \pm 2.7(16.8-30.3)$ & 0.9 \\
\hline Diagnosis PSA, ng/ml & $16.0 \pm 12.5(0.4-61.0)$ & $38.9 \pm 114.7(4.1-946.6)$ & 0.1 \\
\hline Prostate volume, $\mathrm{ml}$ & $49.2 \pm 15.8(13.5-100.7)$ & $51.5 \pm 18.5(16.7-122.5)$ & 0.4 \\
\hline Clinical stage, n (\%) & & & 0.8 \\
\hline $\mathrm{T} 1$ & $30(41.7)$ & $33(40.2)$ & \\
\hline $\mathrm{T} 2$ & $38(52.8)$ & $46(56.1)$ & \\
\hline T3 & $4(5.6)$ & $3(3.7)$ & \\
\hline Diagnosis Gleason, n (\%) & & & 0.2 \\
\hline$\leq 6$ & $31(43.1)$ & $26(31.7)$ & \\
\hline 7 & $31(43.1)$ & $37(45.1)$ & \\
\hline$\geq 8$ & $10(13.9)$ & $19(23.2)$ & \\
\hline Diagnosis method, n (\%) & & & 0.5 \\
\hline Biopsy & $66(91.7)$ & $78(95.1)$ & \\
\hline TURP & $6(8.3)$ & $4(4.9)$ & \\
\hline IIEF-5 $\mathrm{Q}_{2} \geq 3$ pre-surgery, $\mathrm{n}(\%)$ & $49(68.1)$ & $47(57.3)$ & 0.2 \\
\hline \multicolumn{4}{|l|}{ Comorbid condition, n (\%) } \\
\hline$C A D$ & $9(12.5)$ & $10(12.2)$ & 1.0 \\
\hline $\mathrm{DM}$ & $12(16.7)$ & $17(20.7)$ & 0.5 \\
\hline $\mathrm{HBP}$ & $38(52.8)$ & $39(47.6)$ & 0.5 \\
\hline COPD & $8(11.1)$ & $4(4.9)$ & 0.2 \\
\hline CVD & $4(5.6)$ & $6(7.3)$ & 0.8 \\
\hline
\end{tabular}

$B M I$ body mass index, CAD coronary artery disease, COPD chronic obstruction pulmonary diseases, CVD cerebrovascular diseases, DM diabetes mellitus, $H B P$ high blood pressure, TURP transurethral resection of prostate

IIEF-5 Q2: International Index of Erectile Function-5, question NO.2. "When you had erections with sexual stimulation, how often was your erection hard enough for penetration during the last 3 months?" The following responses were available: "No sexual activity" (0); "Almost never or never" (1); "A few times (much less than half the time)" (2); "Sometimes (about half the time)" (3); "Most times (much more than half the time)" (4); and "Almost always or always" (5)

RP decision because of complications. Unfortunately, there is so far no universal definition of continence up to now, which makes the morbidity of continence post-RP vary [6]. As literatures reported, ImC varied from 18 [7] to $63.5 \%$ [8], while continence at 3 months from 45 [9] to $82 \%$ [10], and continence at 12 months from 79.8 [2] to $91 \%$ [11]. In consideration of urinary consequences on record, morbidity of incontinence after RP in real world could probably be higher than reported [12]. Grivas N et al. [13] pointed out that continence at 12 months postsurgery was only $49.2 \%$ with strict definition.

The debate between cancer free and continence still lacks conclusion. Routinely, the more tissue near the tumor incised, the better tumor control. But it also means more potential functional structures to be cut, and incontinence is more likely to happen. Therefore, the discovery of landmark structure for urinary continence is needed. There are many hypotheses, such as membrane urethra length, urethral sphincter complex, detrusor apron of bladder neck, pelvic floor musculature, DVC, and NVB [3], etc. Asimakopoulos AD et al. [14] preferred complete periprostatic anatomy preservation to protect maximal functional structure and got $100 \%$ continence ( $\leq 1$ pad per day) just at the time of catheter removal. However, this procedure may not be suitable for patients with higher tumor stage. Here we suppose DF to be the answer, particularly for the early-term and mid-term urinary control after RP.

DF has been demonstrated to be a multiple-layer structure both in cadaveric studies $[15,16]$ and histologic studies $[17,18]$ on specimen of RP. At the central-post direction of prostate and proximal of urethra, DF's fascicles tend to fuse and adhere with PC to form a dorsal raphe (DR) $[16,18]$. The tendinous DR, which extends distally to prostate apex and ends at perineal tendon, may act as a fulcrum to support prostate and proximal urethra [19]. At the lateral-post direction of prostate, DF disperses to connect with LAF (Fig. 2). Dalpiaz et al. [19] described DF as part of musculofascial suspension system, stabilizing prostate apex and proximal urethra. Interestingly, there was similar view on stress urinary incontinence (SUI) of females. DeLancey [20] 
Table 2 Outcomes of surgery

\begin{tabular}{|c|c|c|c|}
\hline Group & DFS, n (\%) & Control, n (\%) & $P$ \\
\hline \multicolumn{4}{|l|}{ Mean \pm Std (Range) } \\
\hline Surgery duration, min & $153.2 \pm 66.4(100-400)$ & $188.3 \pm 65.1(90-480)$ & $<0.01$ \\
\hline Blood loss, ml & $143.1 \pm 107.2(20-800)$ & $132.4 \pm 136.9(20-1000)$ & 0.6 \\
\hline NVB sparing & & & $<0.01$ \\
\hline Bilateral & $27(37.5)$ & $24(29.3)$ & \\
\hline Unilateral & $13(18.1)$ & $2(2.4)$ & \\
\hline None & $32(44.4)$ & $56(68.3)$ & \\
\hline LND & $63(87.5)$ & $74(90.2)$ & 0.6 \\
\hline pT & & & 0.5 \\
\hline TO & $1(1.4)$ & $0(0)$ & \\
\hline $\mathrm{T} 2$ & $53(73.6)$ & $57(69.5)$ & \\
\hline $\mathrm{T} 3$ & $18(25.0)$ & $25(30.5)$ & \\
\hline Gleason scores & & & 0.1 \\
\hline 0 & $1(1.4)$ & $0(0)$ & \\
\hline$\leq 6$ & $17(23.6)$ & $9(11)$ & \\
\hline 7 & $38(52.8)$ & $50(61)$ & \\
\hline$\geq 8$ & $16(22.2)$ & $23(28)$ & \\
\hline Positive LN & $0(0)$ & $3(3.7)$ & 0.2 \\
\hline SV invasion & $7(9.7)$ & $18(22)$ & 0.04 \\
\hline PSM & $15(20.8)$ & $17(20.7)$ & 1.0 \\
\hline Sites of PSM & & & 0.3 \\
\hline One-site (location; \%) & 13 (5 basal, 7 apical, 1 post-lateral; 18\%) & 11 (2 basal, 8 apical, 1 post-lateral; 13.4\%) & \\
\hline Multiple-sites (locations; \%) & 2 (2 apical and post-lateral; $2.8 \%)$ & $\begin{array}{l}6 \text { (5 apical and basal, } 1 \text { apical, basal and post- } \\
\text { lateral; } 7.3 \%)\end{array}$ & \\
\hline Post-lateral PSM & $3(4.2 \%)$ & $2(2.4 \%)$ & 0.7 \\
\hline IIEF-5 $\mathrm{Q}_{2} \geq 3$ post-surgery & $25(34.7)$ & $14(17.1)$ & 0.01 \\
\hline Continence & & & $<0.01$ \\
\hline Immediate & $60(83.3)$ & $11(13.4)$ & $<0.01$ \\
\hline 3 months- & $65(90.3)$ & $25(30.5)$ & $<0.01$ \\
\hline 6 months- & $66(91.7)$ & $53(64.6)$ & $<0.01$ \\
\hline 12 months- & $67(93.1)$ & $66(80.5)$ & 0.02 \\
\hline
\end{tabular}

LND lymph node dissection, NVB nerve vascular bundle, PSM positive surgical margin, SV seminal vesicles

delineated endopelvic fascia and anterior vaginal wall as the hammock-like supportive layer of urethra, which could stabilize and help to close urethra during cough. Sling, placing a supportive material behind urethra, had been a staple procedure for SUI and withstood the test of time [21]. Back to continence after RP, we hypothesized "hammock theory" still work on and preferred DF to be the critical structure (Figs. 1, 2 and 4), which could uplift vesicourethral anastomosis. Meanwhile, DR just acted as the fulcrum beneath urethra and contributed to closure of it when abdomen pressure increased. Hence, together with DR (also part of DF), DF was supposed to be the critical landmark for continence post RP. Our research also proved that DFS could significantly improve $\operatorname{ImC}(O R=26.4, P<0.01)$. However, because of individual difference, DF or DR could not be kept intact in every operation. So, we proposed a grading system for DFS procedure and our study showed that different grades can indicate different continence prognosis after RP (Fig. 4).

Considering that the scattering neurovascular plexus, which innervates corpora cavernosa and sphincter complex, is embedded in the multiple-layers of DF [3, 22], there was a minority of nerve fibers located in front of DF which would be dissected inevitably [23], while most of them are located in post-lateral and post regions of prostate [3] (Fig. 1). Tewari et al. [24] proposed a nerve-sparing (NS) grading system based on "landmark vein (LV)" lateral to prostate. An intra-fascial dissection was defined as grade-1, while an extra-fascial dissection was defined as grade-4. Srivastava et al. [25] demonstrated that grade- 1 achieved more early continence than grade- 4 (71.8\% vs 43.5\%), which may account for incomplete continence situation with intact DF. 


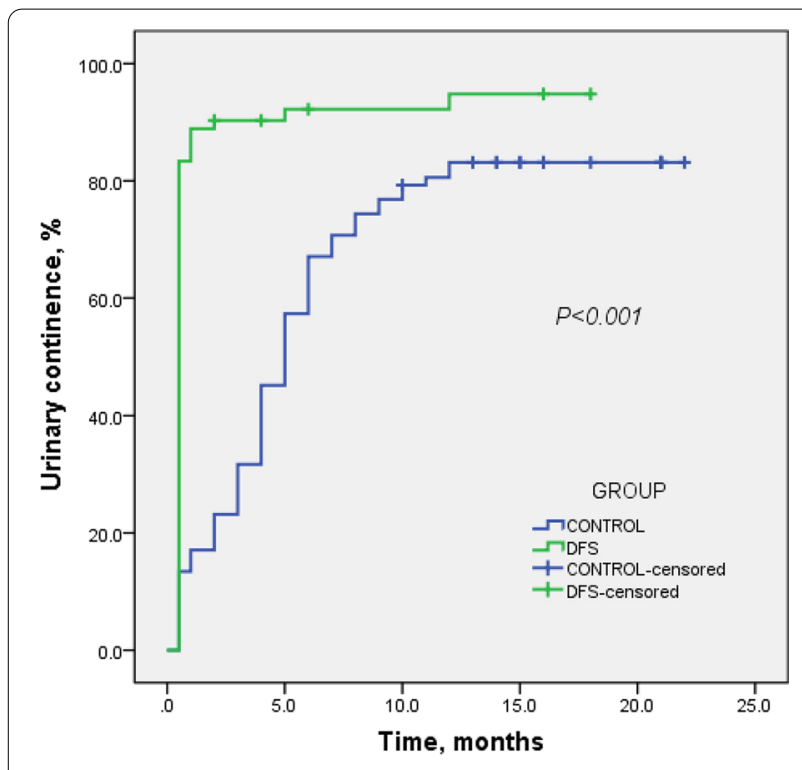

Fig. 3 Kaplan-Meier analysis for time to urinary continence post-surgery

Table 3 Logistic regression analysis for predictors of immediate continence

\begin{tabular}{|c|c|c|c|c|}
\hline \multirow[t]{2}{*}{$\operatorname{ImC}$} & \multicolumn{2}{|l|}{ Univariate } & \multicolumn{2}{|l|}{ Multi-variate } \\
\hline & OR $(95 \% \mathrm{Cl})$ & $P$ & OR $(95 \% \mathrm{Cl})$ & $P$ \\
\hline Surgery type & & $<0.01$ & & 0.6 \\
\hline Mmi-RRP vs LRP & $13.0(5.7-29.7)$ & $<0.01$ & $1.9(0.4-8.7)$ & 0.4 \\
\hline RARP vs LRP & $1.2(0.4-4.0)$ & 0.7 & $0.8(0.2-3.6)$ & 0.7 \\
\hline LND, Yes vs No & $0.7(0.3-2.0)$ & 0.6 & & \\
\hline Gleason score & $0.7(0.5-0.9)$ & 0.02 & $0.9(0.5-1.6)$ & 0.8 \\
\hline $\begin{array}{l}\text { SV invasion, Yes } \\
\text { vs No }\end{array}$ & $0.2(0.1-0.7)$ & $<0.01$ & $0.3(0.1-1.3)$ & 0.1 \\
\hline PSM, Yes vs No & $0.9(0.4-1.9)$ & 0.8 & & \\
\hline $\begin{array}{l}\text { TURP before, Yes } \\
\text { vs No }\end{array}$ & $1.2(0.3-4.3)$ & 0.8 & & \\
\hline Diagnosis PSA & $1.0(0.992-1.003)$ & 0.4 & & \\
\hline $\begin{array}{l}\text { IIEF-5 } Q_{2} \text { pre- } \\
\text { surgery }\end{array}$ & $1.4(1.0-1.9)$ & 0.03 & $1.6(0.9-2.7)$ & 0.1 \\
\hline Prostate volume & $1.0(0.98-1.01)$ & 0.6 & & \\
\hline Age & $1.0(0.91-1.02)$ & 0.2 & $1.0(0.9-1.1)$ & 0.6 \\
\hline BMI & $0.9(0.8-1.1)$ & 0.3 & & \\
\hline Surgery duration & $1.0(0.98-0.99)$ & $<0.01$ & $1.0(0.981-1.002)$ & 0.1 \\
\hline Blood loss & $1.0(0.996-1.001)$ & 0.3 & & \\
\hline NVB sparing & & 0.01 & & 0.9 \\
\hline Unilateral vs No & $4.8(1.4-16.4)$ & 0.01 & $0.8(0.1-4.3)$ & 0.8 \\
\hline Bilateral vs No & $2.1(1.1-4.3)$ & 0.04 & $1.1(0.3-3.8)$ & 0.9 \\
\hline $\begin{array}{l}\text { DF sparing, Yes } \\
\text { vs No }\end{array}$ & $32.3(13.3-78.4)$ & $<0.01$ & $26.4(8.4-83.3)$ & $<0.01$ \\
\hline
\end{tabular}

$B M I$ body mass index, $C l$ confidence interval, ImC immediate continence, $L N D$ lymph node dissection, NVB nerve vascular bundle, OR odds ratio, PSM positive surgical margin, $S V$ seminal vesicles
DF-sparing technique doesn't equal to complete periprostatic anatomy preservation or intra-fascial dissection. DFS procedure emphasizes dissecting before anterior layer of DF to protect the whole DF fascicles and the majority of neurovascular fibers, which is a procedure with a specific target to be spared, making the incision area selective but thorough. Whereas complete peri-prostate sparing technique aims to preserve functional structure as much as possible [14]. However, good functional recovery may sacrifice safety of tumor control. DF-targeted sparing procedure provides a compromised solution to the dilemma of urinary- or tumor-control.

With the same aim at preserving continence, Retzius-sparing (RS) technique puts more emphasis on preserving the structure in front of prostate [26]. RS was supposed to suspend and stabilize the bladder and anastomosis which might contribute to fast recovery of continence [26]. Compared with standard RP, lots of researches reported Retzius-sparing RP (RSRP) with better continence in short term, especially $\operatorname{ImC}[27,28]$. Given that more neurovascular plexus located post-lateral direction $[3,23]$, DFS might result in better continence from another perspective theoretically, but more prospective randomized controlled studies were needed to clarify that.

In our research, Group DFS achieved 83.3\% ImC, 90.3\% continence in 3 months, $91.7 \%$ in 6 months, $93.1 \%$ in 12 months (Fig. 3), better than Group Control at every time point with no difference in PSM $(20.8 \%$ vs $20.7 \%$, $P=1.0$ ), especially no difference of PSM in post-lateral direction of prostate $(4.2 \%$ vs $2.4 \%, P=0.7)$.

Another key point to protect neurovascular plexus is the limited usage of energy devices, such as ultrasonic or electronic scalpels, bipolar coagulator, especially during prostate apex anatomy [29], in which nerve fibers penetrate DF or periprostatic tissue to innervate urethral sphincter. The electrical and thermal conduction may cause extra damage to neurovascular fibers nearby. Thereby, "blunt", or "cold" dissection for prostate apex with finger, forceps, or scissors is preferred. The NS grading system proposed by Patel et al. [30] proved the idea. In Patel's system, grade 5 NS was performed between "landmark artery (LA)" lateral to prostate and PC with neither sharp dissection nor energy devices, which resulted in complete nerve sparing (>95\%). Grade 4 NS (75\%) was also performed between LA and PC with sharp dissection but without energy devices.

Last but not least, we preferred to pay more attention to ImC post RP. Temml et al. [31] testified that QoL wasn't related to duration of incontinence but frequency and degree of incontinence, need for pads, etc. Coyne et al. [32] pointed out remarkable prevalence of $19.1 \%$ anxiety and $6.6 \%$ depression in patients with urinary 

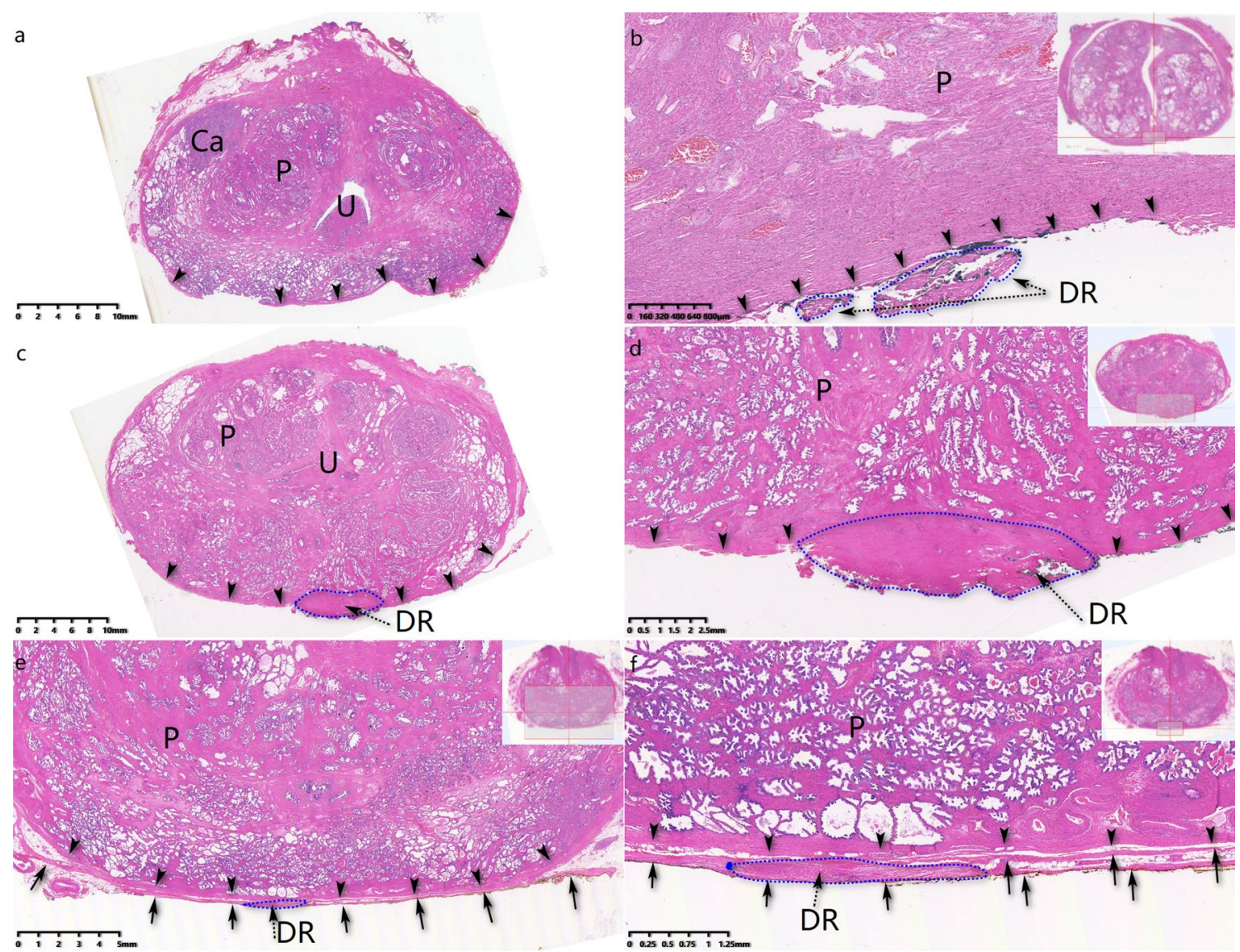

Fig. 4 Different grades of DFS in RP, stained by hematoxylin and eosin. a In Grade-1 DF sparing procedure, neither DF nor DR was cut with prostate b In Grade-2 DFS procedure, DF was preserved while DR fragments removed with prostate. $\mathbf{c}, \mathbf{d}$ In Grade-2 DFS procedure, DF spared successfully while DR was totally cut away. e-f Grade-3 DFS was defined as neither DF nor DR spared. Black arrow head: prostate capsule; Ca: prostate cancer; DR: dorsal raphe (show in blue dot line circle); P: prostate; U: urethra. Black arrow: DF; Black arrow head: PC

incontinence (UI). Anxiety may trigger and aggravate UI in return. So better ImC may guarantee not only "extra" better continence in the future but also positive mental health.

Indeed, there are limitations in present research including small sample size, retrospective, and lack of randomization. Therefore, a prospective randomized controlled study with larger sample size should be organized for further verification.

\section{Conclusion}

Denonvilliers' fascia was supposed to act as the fulcrum and hammock for urinary control after RP. We recommend to preserve DF, minimize utility of energy devices during dissecting, which could probably contribute to best continence after RP without increase of PSM.

\section{Abbreviations}

BMI: Body mass index; CAD: Coronary artery disease; COPD: Chronic obstruction pulmonary diseases; CVD: Cerebrovascular diseases; DM: Diabetes mellitus: DF: Denonvillier's fascia; DFS: DF-sparing: DR: Dorsal raphe; DVC: Dorsal vascular complex; HBP: High blood pressure; HE: Hematoxylin and eosin; IFT: Inter fascial tissue; IIEF-5: International Index of Erectile Function-5: ImC: Immediate continence; LAF: Levator ani fascia; LND: Lymph node dissection; LRP: Laparoscopic radical prostatectomy; Mmi-RRP: Mini-incision retropubic radical prostatectomy; NVB: Neurovascular bundle; ORP: Open radical prostatectomy; PC: Prostate capsule; PSM: Positive surgical margin; RARP: Robotic-assisted radical prostatectomy; RP: Radical prostatectomy; RS: Retzius sparing; RSRP: Retzius sparing radical prostatectomy; TURP: Transurethral resection of prostate; SUI: Stress urinary incontinence; SV: Seminal vesicles; VD: Vas deferens.

\section{Acknowledgements}

We sincerely thank Ms. Miao Gong for production of pathological sections, and Dr. Yuan Ji for support in pathological image scanning and enlightening advices.

\section{Authors' contributions}

Project developed by HW, JMG. Manuscript written by XWL, edited by HW, CH and SHZ. Data collected by FY, ZFG, WYL and JC, analyzed by JQH, MKH and JWW. Pathological section managed and analyzed by XS.

\section{Funding}

This research was supported by Development of Smart Healthcare from Zhongshan Hospital 2020ZHZS20. 


\section{Availability of data and materials}

All data generated or analyzed during this study are included in this published article.

\section{Declarations}

\section{Ethics approval and consent to participate}

The study was performed in accordance with the Declaration of Helsinki. The ethical committees of Minhang Hospital approved the retrospective multicentric study. Due to the retrospective nature of the study, informed consent was waived. The ethical committees of Minhang Hospital were listed as follows: Yanping Zhao, Li Feng, Bin Han, Xiwen Gao, Daowen Jiang, Xiaofan Yin, Wei $\mathrm{Hu}$, Fulin Xu.

\section{Consent for publication}

Not applicable.

\section{Competing interests}

The authors declare that they have no competing interests.

\section{Author details}

'Department of Urology, Minhang Hospital, Fudan University, Shanghai 201199 , China. ${ }^{2}$ Department of Urology, Zhongshan Hospital, Fudan University, Fenglin Rd 130, Shanghai 200032, China. ${ }^{3}$ Department of Pathology, Minhang Hospital, Fudan University, Shanghai 201199, China. ${ }^{4}$ Department of Urology, Xuhui Hospital, Fudan University, Shanghai 200031, China.

Received: 7 September 2021 Accepted: 6 December 2021 Published online: 17 December 2021

\section{References}

1. Siegel RL, Miller KD, Jemal A. Cancer statistics, 2019. CA Cancer J Clin. 2019;69(1):7-34. https://doi.org/10.3322/caac.21551.

2. Haglind E, Carlsson S, Stranne J, Wallerstedt A, Wilderäng U, Thorsteinsdottir $\mathrm{T}$, et al. Urinary incontinence and erectile dysfunction after robotic versus open radical prostatectomy: a prospective, controlled, nanrandomised trial. Eur Urol. 2015;68(2):216-25. https://doi.org/10. 1016/j.eururo.2015.02.029.

3. Walz J, Epstein JI, Ganzer R, Graefen M, Guazzoni G, Kaouk J, et al. A critical analysis of the current knowledge of surgical anatomy of the prostate related to optimisation of cancer control and preservation of continence and erection in candidates for radical prostatectomy: an update. Eur Urol. 2016;70(2):301-11. https://doi.org/10.1016/j.eururo. 2016.01.026.

4. Grasso AA, Mistretta FA, Sandri M, Cozzi G, De Lorenzis E, Rosso M, et al. Posterior musculofascial reconstruction after radical prostatectomy: an updated systematic review and a meta-analysis. BJU Int. 2016;118(1):2034. https://doi.org/10.1111/bju.13480.

5. Albkri A, Girier D, Mestre A, Costa P, Droupy S, Chevrot A. Urinary incontinence, patient satisfaction, and decisional regret after prostate cancer treatment: a French national study. Urol Int. 2018;100(1):50-6. https://doi. org/10.1159/000484616.

6. Liss MA, Osann K, Canvasser N, Chu W, Chang A, Gan J, et al. Continence definition after radical prostatectomy using urinary quality of life: evaluation of patient reported validated questionnaires. J Urol. 2010;183(4):1464-8. https://doi.org/10.1016/j.juro.2009.12.009.

7. John $\mathrm{H}$, Hauri D. Seminal vesicle-sparing radical prostatectomy: a novel concept to restore early urinary continence. Urology. 2000;55(6):820-4. https://doi.org/10.1016/s0090-4295(00)00547-1.

8. Moinzadeh A, Shunaigat AN, Libertino JA. Urinary incontinence after radical retropubic prostatectomy: the outcome of a surgical technique. BJU Int. 2003;92(4):355-9. https://doi.org/10.1046/j.1464-410x.2003.04348.x.

9. Hollabaugh RS, Dmochowski RR, Kneib TG, Steiner MS. Preservation of putative continence nerves during radical retropubic prostatectomy leads to more rapid return of urinary continence. Urology. 1998:51(6):960-7. https://doi.org/10.1016/s0090-4295(98)00128-9.
10. Walsh PC, Marschke PL. Intussusception of the reconstructed bladder neck leads to earlier continence after radical prostatectomy. Urology. 2002;59(6):934-8. https://doi.org/10.1016/s0090-4295(02)01596-0.

11. Coughlin GD, Yaxley JW, Chambers SK, Occhipinti S, Samaratunga H, Zajdlewicz L, et al. Robot-assisted laparoscopic prostatectomy versus open radical retropubic prostatectomy: $24-$ month outcomes from a randomised controlled study. Lancet Oncol. 2018;19(8):1051-60. https:// doi.org/10.1016/S1470-2045(18)30357-7.

12. Nelson JB. The ongoing challenge of urinary incontinence after radical prostatectomy. J Urol. 2017;198(6):1223-5. https://doi.org/10.1016/j.juro. 2017.09.053.

13. Grivas N, van der Roest R, Schouten D, Cavicchioli F, Tillier C, Bex A, et al. Quantitative assessment of fascia preservation improves the prediction of membranous urethral length and inner levator distance on continence outcome after robot-assisted radical prostatectomy. Neurourol Urodyn. 2018;37(1):417-25. https://doi.org/10.1002/nau.23318.

14. Asimakopoulos AD, Annino F, D'Orazio A, Pereira CF, Mugnier C, Hoepffner $J$, et al. Complete periprostatic anatomy preservation during robot-assisted laparoscopic radical prostatectomy (RALP): the new pubovesical complex-sparing technique. Eur Urol. 2010;58(3):407-17. https:// doi.org/10.1016/j.eururo.2010.04.032.

15. Ghareeb WM, Wang X, Chi P, Wang W. The "multilayer" theory of Denonvilliers'fascia: anatomical dissection of cadavers with the aim to improve neurovascular bundle preservation during rectal mobilization. Colorectal Dis. 2020;22(2):195-202. https://doi.org/10.1111/codi.14850.

16. Xu Z, Chapuis PH, Bokey L, Zhang M. Denonvilliers' fascia in men: a sheet plastination and confocal microscopy study of the prerectal space and the presence of an optimal anterior plane when mobilizing the rectum for cancer. Colorectal Dis. 2017. https://doi.org/10.1111/codi.13906.

17. Secin FP, Karanikolas N, Gopalan A, Bianco FJ, Shayegan B, Touijer K, et al. The anterior layer of Denonvilliers' fascia: a common misconception in the laparoscopic prostatectomy literature. J Urol. 2007;177(2):521-5. https://doi.org/10.1016/j.juro.2006.09.028.

18. Kiyoshima K, Yokomizo A, Yoshida T, Tomita K, Yonemasu H, Nakamura M, et al. Anatomical features of periprostatic tissue and its surroundings: a histological analysis of 79 radical retropubic prostatectomy specimens. Jpn J Clin Oncol. 2004;34(8):463-8. https://doi.org/10.1093/jjco/hyh078.

19. Dalpiaz O, Anderhuber F. The fascial suspension of the prostate: a cadaveric study. Neurourol Urodyn. 2017;36(4):1131-5. https://doi.org/10.1002/ nau.23073.

20. DeLancey JO. Structural support of the urethra as it relates to stress urinary incontinence: the hammock hypothesis. Am J Obstet Gynecol. 1994;170(6):1713-20. https://doi.org/10.1016/s0002-9378(94)70346-9.

21. Schreiner G, Beltran R, Lockwood G, Takacs EB. A timeline of female stress urinary incontinence: how technology defined theory and advanced treatment. Neurourol Urodyn. 2020;39(6):1862-7. https://doi.org/10.1002/ nau. 24407.

22. Muraoka K, Hinata N, Morizane S, Honda M, Sejima T, Murakami G, et al. Site-dependent and interindividual variations in Denonvilliers' fascia: a histological study using donated elderly male cadavers. BMC Urol. 2015:15:42. https://doi.org/10.1186/s12894-015-0034-5.

23. Kinugasa Y, Murakami G, Uchimoto K, Takenaka A, Yajima T, Sugihara K. Operating behind Denonvilliers' fascia for reliable preservation of urogenital autonomic nerves in total mesorectal excision: a histologic study using cadaveric specimens, including a surgical experiment using fresh cadaveric models. Dis Colon Rectum. 2006;49(7):1024-32. https://doi.org/ 10.1007/s10350-006-0557-7.

24. Tewari AK, Srivastava A, Huang MW, Robinson BD, Shevchuk MM, Durand $M$, et al. Anatomical grades of nerve sparing: a risk-stratified approach to neural-hammock sparing during robot-assisted radical prostatectomy (RARP). BJU Int. 2011;108(6 Pt 2):984-92. https://doi.org/10.1111/j.1464410X.2011.10565.x.

25. Srivastava A, Chopra S, Pham A, Sooriakumaran P, Durand M, Chughtai B, et al. Effect of a risk-stratified grade of nerve-sparing technique on early return of continence after robot-assisted laparoscopic radical prostatectomy. Eur Urol. 2013;63(3):438-44. https://doi.org/10.1016/j.eururo.2012. 07.009.

26. Galfano A, Ascione A, Grimaldi S, Petralia G, Strada E, Bocciardi AM. A new anatomic approach for robot-assisted laparoscopic prostatectomy: a feasibility study for completely intrafascial surgery. Eur Urol. 2010;58(3):45761. https://doi.org/10.1016/j.eururo.2010.06.008. 
27. Rosenberg JE, Jung JH, Edgerton Z, Lee H, Lee S, Bakker CJ, et al. Retzius-sparing versus standard robot-assisted laparoscopic prostatectomy for the treatment of clinically localized prostate cancer. BJU Int. 2021;128(1):12-20. https://doi.org/10.1111/bju.15385.

28. Umari P, Eden C, Cahill D, Rizzo M, Eden D, Sooriakumaran P. Retzius-sparing versus standard robot-assisted radical prostatectomy: a comparative prospective study of nearly 500 patients. J Urol. 2021;205(3):780-90. https://doi.org/10.1097/JU.0000000000001435.

29. Tewari A, Takenaka A, Mtui E, Horninger W, Peschel R, Bartsch G, et al. The proximal neurovascular plate and the tri-zonal neural architecture around the prostate gland: importance in the athermal robotic technique of nerve-sparing prostatectomy. BJU Int. 2006;98(2):314-23. https://doi.org/ 10.1111/j.1464-410X.2006.06266.x.

30. Schatloff O, Chauhan S, Sivaraman A, Kameh D, Palmer KJ, Patel VR. Anatomic grading of nerve sparing during robot-assisted radical prostatectomy. Eur Urol. 2012;61(4):796-802. https://doi.org/10.1016/j. eururo.2011.12.048

31. Temml C, Haidinger G, Schmidbauer J, Schatzl G, Madersbacher S. Urinary incontinence in both sexes: prevalence rates and impact on quality of life and sexual life. Neurourol Urodyn. 2000;19(3):259-71.

32. Coyne KS, Kvasz M, Ireland AM, Milsom I, Kopp ZS, Chapple CR. Urinary incontinence and its relationship to mental health and health-related quality of life in men and women in Sweden, the United Kingdom, and the United States. Eur Urol. 2012;61(1):88-95. https://doi.org/10.1016/j. eururo.2011.07.049.

\section{Publisher's Note}

Springer Nature remains neutral with regard to jurisdictional claims in published maps and institutional affiliations.
Ready to submit your research? Choose BMC and benefit from:

- fast, convenient online submission

- thorough peer review by experienced researchers in your field

- rapid publication on acceptance

- support for research data, including large and complex data types

- gold Open Access which fosters wider collaboration and increased citations

- maximum visibility for your research: over 100M website views per year

At BMC, research is always in progress.

Learn more biomedcentral.com/submissions 